\title{
Prediction Equation Study of Road and Regolith Erosion in Production and Construction Projects
}

\author{
Nan Yan ${ }^{1,2, a *}$, Wei Qin 1, 2,b, Changqing Zuo ${ }^{1,2, c}$, Zhe Yin ${ }^{1,2, d}$, Bai Li $^{1,2, e}$, \\ Qiankun Guo, ${ }^{1,2,}$, Zhijie Shan ${ }^{1,2, g}$, Zhaoyan Wang ${ }^{1,2, h}$
}

${ }^{1}$ State Key Laboratory of Simulation and Regulation of Water Cycle in River Basin, China Institute of Water Resources and Hydropower Research, Beijing 100048, China;

${ }^{2}$ Research Center on Soil and Water Conservation of the Ministry of Water Resources, China Institute of Water Resources and Hydropower Research, Beijing 100048, China;

ayannan8521@sina.com, 'binwei_office@sina.com, 'czuochq@sina.com, dyinzhe-2002@163.com, elbyn1986@hotmail.com, 'guoqiankun@iwhr.com, ${ }^{9}$ shanzhj@iwhr.com, hzhaoys@163.com

Keywords: road erosion; surface regolith erosion; production and construction projects; prediction equation

Abstract. Unpaved road and road surface regolith are taken as the research objects in this study, 15 main roads in production and construction projects in Shannxi Province and Inner Mongolia Autonomous Region were investigated, road simulate and artificial rainfall experiments were carried out. The results showed that the road erosion and surface regolith erosion are significantly related to precipitation, slope and regolith thickness, based on the experiments results and literature review, the road and surface regolith erosion prediction equations were established, the imitative results are at significant level $(\mathrm{R}=0.764,0.937)$, another set of artificial rainfall experiments were carried out for the test of prediction equations, through the verification of measured data, the prediction values have a significant linear relationship with the measured values $(p<0.01)$, determination coefficient are 0.80 and 0.74 respectively, thus, the prediction equation is suitable for the erosion prediction of roads in production and construction projects, the equation itself is theoretically simple and each parameter can be directly detected in the field, it can be easily operated and used. This study provides new view angle and basis for accurate and comprehensive calculation of soil and water erosion in production and construction projects.

\section{Introduction}

In the production and construction projects, varies of transportation, human and livestock grinding resulted in amounts of regolith accumulated on the top of paved and unpaved roads. Under rainfall or wind, it's easily to have erosion or dust problems, where the soil erosion from unpaved road is the main contribution to the sediment deposition in remote area, forests and river downstream ${ }^{[1-3]}$. At present, there are loads of research about road soil erosion prediction in production and construction projects, but mainly focus on embankment, cutting, slag disposal pit and building area, slope excavation and side slope ${ }^{[4-8]}$, very few study about quantitative study of soil erosion caused by the surface regolith of the road. Road erosion prediction including surface regolith erosion is required to overall and accurately predict the soil erosion of production and construction projects, also necessary for the implementation of soil and water conservation responsibility. There are two major road erosion prediction methods which are adopted home and abroad: model prediction and RS/GIS statistical analysis prediction ${ }^{[9-10]}$, where model prediction can be summarized into two types, model based on process or empirical statistical model ${ }^{[11]}$, process model is established by describing the soil erosion physical process which based on the rainfall and road situation, for example, the classic road erosion prediction model KINEROS and KINEROS $2^{[12-15]}$, the model is event-driven, aiming to describe dynamic and dispersive road surface runoff, and the prediction equations modified from the USLE and WEPP models which are used to describe soil erosion in farmland ${ }^{[16-17]}$. Empirical statistical model is firstly obtaining impact indexes by observation and statistical analyze, and then to confirm the relationship between soil erosion 
and each index. Empirical statistical models about road erosion including: Megahan et al established the road erosion prediction equation based on rainfall erosion intensity, vegetation coverage, slope aspect and slope gradient ${ }^{[18]}$; The model set up by Anderson mainly considered the influence brought by catchment area and gradient ${ }^{[19]}$; Xu's model is based on the rainfall intensity and rainfall capacity which summarized from nature rainfall observation in Qinghai-Tibet highway by runoff plot ${ }^{[20]}$; Qiu did artificial rainfall experiments in access road in Yongan City of Fujian Province and put forward a road erosion prediction model including built time, slope length gradient these main factors ${ }^{[21]}$. These models have selected different research objects, including paved and unpaved roads ${ }^{[22]}$, but there is no single research about the model of road surface regolith erosion. In this study, unpaved roads with frequent traffic and obvious regolith were selected as the object, through the field investigation and indoor artificial rainfall experiments, the road and surface regolith erosion prediction equation is established.

\section{Road erosion prediction equation generalize and impact factor choose}

Road erosion is influenced by many factors, like gradient, length, road service condition, distance between drain points, road surface physical condition, rainfall capacity and rainfall intensity, location and road microtopography ${ }^{[19]}$. The specificity of road erosion is that the road runoff mainly follows the Horton runoff theory, less relates to the road return flow, but closely relates to the rainfall characteristic $^{[23-24]}$. MacDonald did artificial rainfall experiments in Virgin Island, American, and found out that road surface erosion closely related to rainfall capacity, rainfall intensity and surface runoff, where significantly related to the rainfall capacity, while the sediment yield is more relate to slope gradient, and the road surface sediment yield is closely related to the track frequency ${ }^{[24]}$. Qiu set up poles on the mountain roads and found that the soil erosion had a functional relationship with slope gradient and length ${ }^{[21]}$. Lucy et al found that sediment yield of unpaved roads is proportional to the product of slope length and gradient ${ }^{[25]}$. Xu, Yang and Megahan agreed that the road erosion should consider more about rainfall factors like rainfall capacity and intensity ${ }^{[18,20,26,27]}$. In this study, through the literature review and field investigation, we found that rainfall condition and gradient are two domain factors that influence the road erosion, also these two factors are the main indexes for calculating boundary shear stress and sediment transfer capability, and have been widely used in the road erosion prediction models ${ }^{[28-30]}$, and they can be field observed. Thus in this study, rainfall capacity, intensity and gradient are selected to initially establish the road erosion equation, and because the frequent traffic in the constructing and operation process of production and construction projects, piles of surface regolith erosion occurred, the thickness of regolith is also considered in this prediction model, the initial road and surface regolith erosion equation is shown in (1).

$\mathrm{E}=\mathrm{IQ} \theta \mathrm{h}$.

Where, $\mathrm{E}$ is rainfall erosion amount, $\mathrm{t} \cdot \mathrm{hm}^{-2}$; I is rainfall intensity, $\mathrm{mm} \mathrm{min}^{-1}$; $\mathrm{Q}$ is rainfall capacity, $\mathrm{mm} ; \theta$ is slope gradient, ${ }^{\circ} ; \mathrm{h}$ is thickness of regolith, $\mathrm{cm}$.

\section{Materials and methods}

\section{Field investigation}

We selected apple orchard in Changwu, Shaanxi province, Shenmu coal mine in Shaanxi province and Yongli coal mine in Inner Mongolia, 15 main roads were investigated, all of them are unpaved roads, and covered by fine quality loess, some roads have gravel and fly ash on the surface. We chose 48 sampling points, and recorded their name, longitude and latitude, elevation, slope gradient and maximum value, minimum value and average value of regolith thickness, and the top $0-10 \mathrm{~cm}$ soil were 
sampled, bulk density, water content and other physical properties were measured in the lab, results are shown in Table 1.

Table 1. Road surface regolith physical properties through field investigation

\begin{tabular}{ccccccc}
\hline & \multicolumn{2}{c}{ Slope gradient $\left[{ }^{\circ}\right]$} & \multicolumn{2}{c}{ Regolith thickness $[\mathrm{cm}]$} & \multicolumn{2}{c}{ Bulk density $\left[{\left.\mathrm{g} \bullet \mathrm{cm}^{-3}\right]}^{2}\right.$} \\
\hline $0-4^{\circ}$ & $4-10^{\circ}$ & $10-20^{\circ}$ & Sides of Road & $\begin{array}{c}\text { Middle of } \\
\text { Road }\end{array}$ & $\begin{array}{c}\text { Road Bulk } \\
\text { density }\end{array}$ & $\begin{array}{c}\text { Regolith Bulk } \\
\text { density }\end{array}$ \\
$10 \%$ & $80 \%$ & $10 \%$ & $2-4$ & $0.2-2$ & 1.68 & 1.20
\end{tabular}

The results showed that the slope gradient are concentrated between $0^{\circ} \sim 20^{\circ}$, and $80 \%$ are between $4^{\circ} \sim 10^{\circ}$; the regolith on the sides of roads are more thick, about $2 \sim 4 \mathrm{~cm}$, but in the middle of the roads are less than $2 \mathrm{~mm}$; The average road bulk density is $1.68 \mathrm{~g} \cdot \mathrm{cm}^{-3}$ and the average regolith bulk density is $1.20 \mathrm{~g} \cdot \mathrm{cm}^{-3}$ 。 The indoor simulated regolith and road design including surface regolith thickness, bulk density and gradient all adopted the field investigation results.

\section{Indoor simulated experiments}

According to the field investigation, we selected $2^{\circ} 、 4^{\circ} 、 8^{\circ}$ and $16^{\circ}$ as the slope gradients, $0.5 \mathrm{~cm}$ 、 $1 \mathrm{~cm} 、 2 \mathrm{~cm}$ and $4 \mathrm{~cm}$ as the regolith thickness, and the surface regolith were manually allocated. Soil samples collected in the field were sieved by $6 \mathrm{~mm}, 2 \mathrm{~mm}$ and $0.25 \mathrm{~mm}$ nets respectively, then allocated by 7:3 weight percentage. Trial soil tanks were filled by 5 layers of clayey loess, each layer $10 \mathrm{~cm}$, discus was used to continually beat to compact soil until reach the designed bulk density, the trial soil tank is $2 \mathrm{~m} \times 0.5 \mathrm{~m} \times 0.55 \mathrm{~m}$. Before the artificial rainfall experiments, the trial soil tanks were adjusted to designed gradient, and the regolith was laid. A $3 \mathrm{~mm}$ wide white nylon line was set between the simulated road and the regolith at the tank outlet, when white nylon wire exposed, that means surface regolith has been completely eroded, and the lower road erosion begins.

Artificial rainfall experiment was carried out in the artificial rainfall hall in State Key Laboratory of Soil Erosion and Dryland Farming on Loess Plateau of Chinese Academy of Sciences and Ministry of Water Resources. The rainfall intensity were 1.0, 1.5, 2.0 and $2.5 \mathrm{~mm} \cdot \mathrm{min}^{-1}$, and according to the designed regolith thickness and rainfall intensity, the rainfall duration were 39、33、27、21 min with the gradients $2^{\circ} 、 4^{\circ}, 8^{\circ}$ and $16^{\circ}$. There were 64 rainfall experiments in total, runoff producing start time is determined when the runoff coming out the rank, when white nylon wire exposed that is the time road begin to erode. The road surface regolith erosion start and end time and road underlying erosion start time are recorded, the runoff and sediment samples were collected at the outlet of the tank. In this study, the rainfall erosion process is divided into two stages: road surface regolith erosion stage and road underlying erosion stage, the sum of these two stages erosion amount is the total erosion amount of simulated road. Subsection recording and calculation of the road erosion in different stages can be more helpful for understanding the road surface regolith erosion rules, features and the proportion in the whole road erosion.

\section{Statistical analysis}

The relationship between soil erosion and rainfall intensity, rainfall capacity, slope gradient, regolith thickness were assessed by SPSS single factor correlation analysis, the equation of road erosion and surface regolith erosion were established by SPSS curve estimation and regression analysis. 


\section{Road and regolith erosion prediction equation}

\section{Relative factors analysis}

By collecting the effective soil erosion data of the 64 rainfall experiments, the correlation analysis between the parameters and the soil erosion amount per unit was carried out (Table 2). The results showed that the regolith erosion amount was significantly related to the regolith thickness, rainfall capacity and the total erosion amount, while the relationship between regolith erosion and gradient and rainfall intensity were not obvious. This could be explained by that the roads with thinner regolith had shorter rainfall duration according to the design, thus the regolith erosion is more significant related to the rainfall capacity, second is the regolith erosion amount is smaller, only $15 \%$ of the total erosion amount, also the regolith erosion time is shorter, so the effects of gradient to the regolith erosion is not obvious; the total erosion amount is closely related to rainfall intensity, rainfall capacity, gradient and regolith thickness, especially the rainfall characters $(\mathrm{p}<0.01)$ (Table 2$)$.

Table2. Correlation analysis between soil erosion factors

\begin{tabular}{|c|c|c|c|c|c|c|c|}
\hline & & $\begin{array}{l}\text { Rainfall } \\
\text { intensity }\end{array}$ & Rainfall & Grade & $\begin{array}{l}\text { Regolith } \\
\text { thickness }\end{array}$ & $\begin{array}{l}\text { Regolith } \\
\text { erosion } \\
\text { amount }\end{array}$ & $\begin{array}{l}\text { Total } \\
\text { erosion } \\
\text { amount }\end{array}$ \\
\hline \multirow{3}{*}{$\begin{array}{l}\text { Regolith } \\
\text { erosion } \\
\text { amount }\end{array}$} & $\begin{array}{c}\text { Pearson } \\
\text { Pearson } \\
\text { correlation }\end{array}$ & .089 & $.281^{*}$ & .192 & $.478^{* *}$ & 1 & $.490^{*}$ \\
\hline & $\begin{array}{l}\text { Significance } \\
\text { (two-tailed) }\end{array}$ & .482 & .024 & .128 & .000 & - & .000 \\
\hline & $\mathrm{N}$ & 64 & 64 & 64 & 64 & 64 & 64 \\
\hline \multirow[t]{3}{*}{$\begin{array}{l}\text { Total } \\
\text { erosion } \\
\text { amount }\end{array}$} & $\begin{array}{c}\text { Pearson } \\
\text { Pearson } \\
\text { correlation }\end{array}$ & $.637^{* *}$ & $.622^{* *}$ & $.564^{*}$ & $.347^{* *}$ & $.490^{* *}$ & 1 \\
\hline & $\begin{array}{l}\text { Significance } \\
\text { (two-tailed) }\end{array}$ & .000 & .000 & .005 & .005 & .000 & - \\
\hline & $\mathrm{N}$ & 64 & 64 & 64 & 64 & 64 & 64 \\
\hline
\end{tabular}

Note: **. at the 0.01 level (bilateral) significantly related, *. at the 0.05 level. (bilateral) significantly related.

\section{Prediction equation}

The road and surface regolith erosion is caused by comprehensive effects of different factors. The indoor artificial rainfall experiment showed that road and surface regolith erosion have a close relationship with rainfall capacity, slope gradient and regolith thickness these three factors, hence, on the basis of initial established road erosion prediction equation, rainfall capacity, slope gradient and regolith thickness were selected and regression analysis were carried out. The results showed that there was a power function relationship between road and surface regolith erosion amount and the rainfall capacity and slope gradient, and there was an exponential function relationship with regolith thickness.

The production and construction projects road erosion and surface regolith erosion prediction equation is adjusted to (2).

$$
E=a e^{b h} Q^{c} \theta^{d}
$$

Where, $\mathrm{E}$ is the road erosion amount/road surface regolith erosion amount, $\mathrm{t} \cdot \mathrm{hm}^{-2} ; \mathrm{h}$ is regolith thickness, cm; $\mathrm{Q}$ is rainfall capacity, mm; $\theta$ is slope gradient, ${ }^{\circ} ; \mathrm{a}, \mathrm{b}, \mathrm{c}, \mathrm{d}$ are regression coefficients. 


\section{Parameters determination}

128 groups of measured data were used for regression analysis by SPSS, respectively, the results showed that it was significant fitting $(\mathrm{R}=0.7644,0.937)$, thus the equation is feasible for the prediction of road and surface regolith erosion. The regression coefficients of the prediction equation are determined, the road surface regolith erosion prediction equation and the road erosion prediction equation are (3) and (4).

$$
\begin{aligned}
& E=0.53 e^{0.266 h} Q^{0.568} \theta^{0.274} \\
& E=0.03 e^{0.029 h} Q^{1.579} \theta^{0.78}
\end{aligned}
$$

\section{Calibration and validation}

Second batch of artificial rainfall experiment was carried out to verify the established prediction equation. There were 18 rainfall experiments that implemented with the following details: slope gradient: $2^{\circ} 、 4^{\circ} 、 8^{\circ}$; regolith thickness: $1 \mathrm{~cm}, 2 \mathrm{~cm}, 4 \mathrm{~cm}$; and the rainfall intensity: $1.0,2.5 \mathrm{~mm} \cdot \mathrm{min}^{-1}$. After the experiments, the measured results were compared with the predicted results which by substituting the parameters into the prediction equation, the results showed that both road erosion and surface regolith erosion predicted results had a linear relationship with the measured results $(\mathrm{p}<0.01$, $\mathrm{R}^{2}=0.80,0.74$ ) (Fig 1,2). Fully explain the precise of the established production and construction projects road and surface regolith erosion prediction equation.

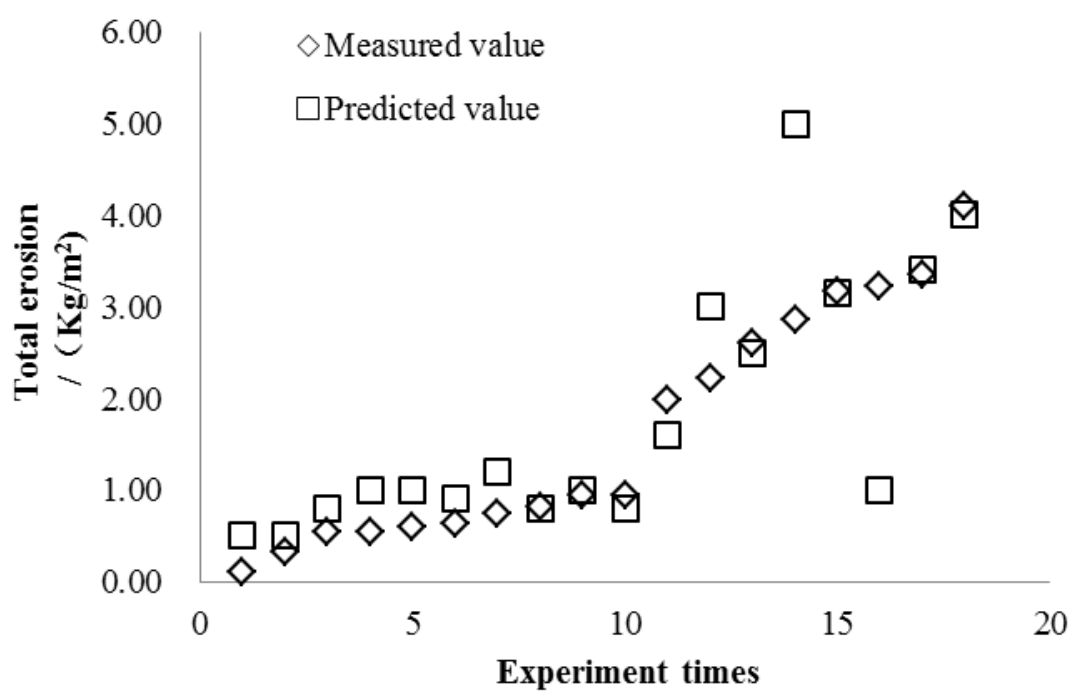

Fig 1. Comparison of measured value and predicted value of road total erosion amount 


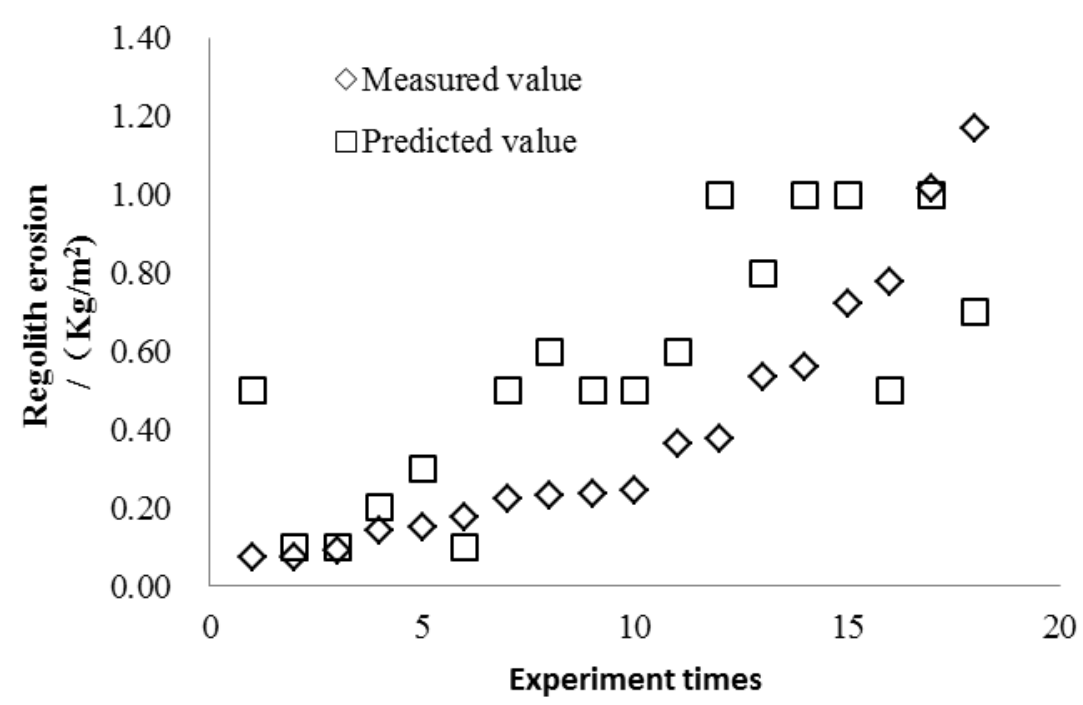

Fig 2. Comparison of measured value and predicted value of road surface regolith erosion amount

\section{Results and discussion}

The indoor artificial rainfall experiment study found that under the rainfall condition, road erosion and regolith erosion are closely related to rainfall factors and slope gradient, this conclusion is agree with Ziegler, MacDonald, Xu Xianli ${ }^{[20,23,24]}$. Through the simulated rainfall erosion experiments we come to know that road regolith erosion is a serious problem in production and construction projects, it is about $18 \%$ of the total erosion. In this study, the effect of regolith thickness was considered, and the results prove that it is significant related to the road erosion. Because the regolith exists in most of unpaved and paved roads, especially in the production and construction projects, the soil erosion from the road surface regolith can't be ignored. This research applied a new angle and proof for the production and construction projects soil erosion prediction.

This study is based on soil erosion principles, related road erosion prediction models and road surface regolith features were considered, the road and surface regolith erosion prediction equation in production and construction projects is established (5).

$$
E=a e^{b h} Q^{c} \theta^{d}
$$

Calibration and validation were performed to ensure the model accuracy, it turned out a good prediction result, and the parameters are easy to obtain, furthermore, it is practicable. In this study the road was simulated by a certain trial tank, and artificial rainfall experiments were implemented indoors, thus the other relevant factors like slope length ${ }^{[25,30]}$, catchment area ${ }^{[19]}$, abandoned time ${ }^{[21]}$, vegetation coverage and rainfall erosion force ${ }^{[18]}$ were not included, field rainfall experiments are suggested to carry out and more factors would be considered in the future study.

\section{Acknowledgements}

This project was funded by the Non-Profit Special Fund of MWR (grant no. 201001036, 201201047).

\section{References}

[1] L.H, MacDonald, D.M. Anderson, W.E. Dietrich, Paradise threatened: land-use and erosion on St John, US Virgin Islands, Environmental Management. 21(1997) 851-863. 
[2] W.L. Hafley, Rural road systems as a source of sediment pollution -a case study, in: Watershed Management, Irrigation and Drainage Division, American Society of Civil Engineers, New York, 1975, pp. 393-405.

[3] T.J. Ward, Sediment yield modeling of roadways, in: S.A. Swaify (Eds.), Soil Erosion and Conservation, Soil Conservation Society of America. Ankeny, Iowa, 1985, pp. 188-199.

[4] L.X. Cao, Y.P. Kong, A.H. Ma,et al, Estimation of road region sediment yield during expressway construction period, Journal of Highway and Transportation Research and Development. 28(2011) 143-148.In Chinese.

[5] Y.J.Liu, T.W.Wang , Z.X.Li, et al, Effects of different vegetation protection measures on erosion prevention of unpaved roadside slopes in Three Gorges Reservoir Area, Chinese Journal of Applied Ecology. 23(2012) 896-902. In Chinese.

[6] T.F.Chen, P.Cui, Prediction of soil erosion on the embankment slope of Xichang to Panzhihua Highway, Sichuan, China, Journal of Chengdu University of Technology (Science \& Technology Edition). 33(2006) 371-375. In Chinese.

[7] T.W. Wang, Y.T.Shan, B.Wang, Analysis and Research of Road Erosion and Slope Protection in Tibet Plateau, Traffic safety and environmental protection, 22(2014) 38-43. In Chinese.

[8] Z.S. Jiang, S. Zhong, F.L. Zheng et al, Prediction model of water erosion on hillslopes, Journal of Sediment Research. 4 (2005) 1-6. In Chinese.

[9] L.Y.Wu, L.J.Yan, Impact of road on soil erosion risk pattern based on RUSLE and GIS: a case study of Hangjinqu highway, Zhuji section, Acta Ecologica Sinica. 34(2014) 5659-5669.

[10] A.X.Chen , M.Li , Z.X.Su , et al, Study on dynamic changes of soil and water loss along highway based on RS /GIS: an example of Yujing expressway, Acta Ecologica Sinica. 31(2011) 3424-3431.

[11] X.L.Xu, K.L.Zhang, X.C.Liu, A Review of Research on Road Erosion, Progress In Geography. 25(2006) 52-61. In Chinese.

[12] A.D. Ziegler, T.W. Giambelluca, R.A.Sutherland, Erosion prediction on unpaved mountain roads in northern Thailand : validation of dynamic erodibility modeling using KINEROS2, Hydrological Processes. 15(2001) 337-358.

[13] A.D. Ziegler, T.W. Giambelluca, R.A.Sutherland, Improved method for modeling sediment transport on unpaved roads using KINEROS2 and dynamic erodibility, Hydrological Processes.16(2002) 3709-3089.

[14] R.E. Smith, D.C. Goodrich, J.N. Quinton, Dynamic, distributed simulation of watershed erosion: the KINEROS2 and EUROSEM models, Journal of Soil and Water Conservation. 50(1995)517-520.

[15] Z.H.Shi, N.F.Fang, L.LI, et al. Modeling erosion processes on unpaved roads using KINEROS2, Geographical Research. 29 (2010) 408-415. In Chinese.

[16] P.N.Lane, G.J. Sheridan, Impact of an unsealed forest road stream crossing : water quality and sediment sources, Hydrol process. 16(2002) 2599-2612.

[17] H. Rhee, J.L. Fridley, R.B. Foltz, Modeling erosion from unpaved forest roads at various levels of geometric detail using the WEPP model, Transactions of the ASAE. 47(2004) 961-968.

[18] W.F. Megahan, Erosion Over Time : a model, USDA- Forest Service Research Paper Report INT-156, Intermountain Research Station,Ogden UT(1974). 
[19] D.M. Anderson, L.H. MacDonald, Modeling road surface sediment production using a vector geographic information system, Earth Surface Processes and Landforms. 23(1998) 95-107.

[20] X.L. Xu, K.L. Zhang, L. Pang, et al, Laws of Soil Erosion on Sideslopes of Qinghai-Tibet Highway, Scientia Geographica Sinica. 26(2006) 211- 215. In Chinese.

[21] R.Z. Qiu, J.W. Fang, Study on soil erosion and prevention measures of forest road in mountain area, Journal of Soil Erosion and Soil and Water Conservation. 3(1997) 50-54. In Chinese.

[22] M.Z. Wang, C.Y. Yang, Z.Y. Xu, et al, Study on Prediction of Soil Erosion on Hard Ground Surface Formed in Road Consruction, Journal of Soil and Water Conservation.16(2002) 77- 79. In Chinese.

[23] A.D. Ziegler, R.A.Sutherland, T.W. Giambelluca, Runoff generation and sediment transport on unpaved roads, paths, and agricultural land surfaces in northern Thailand, Earth Surface Processes and Landforms. 25(2000): 519-534.

[24] L.H. MacDonald, R.W. Sampson, D.M. Anderson, Runoff and road erosion at the plot and road segment scale , St . John, US Virgin Islands, Invited paper for a special issue on roads, Earth Surface Processes and Landforms. 26 (2001) 1-22 .

[25] C.H. Luce, T.A. Black, Spatial and temporal patterns in erosion from forest roads. In influence of urban and forest land uses on the hydrologic-geomorphic responses of watershed, in: M.S. Wigmosta, S.J . Burges (Eds), Water Resources Monographs, American Geophysical Union , Washington D.C, 2001, pp.165-178.

[26] C.Y. Yang, M.Z. Wang, Z.Y. Xu, et al. Study on Soil Erosion Prediction on Embankment Slope of Qin-Shen Passenger Dedicated Line, Journal of Soil and Water Conservation. 15(2001) 14-16. In Chinese.

[27] J. Croke, S. Mockler, Gully initiation and road-to-stream linkage in a forested catchment, southeastern Australia, Earth Surface Process and Landforms. 26 (2001) 205-217.

[28] I.D. Moore, I. P. Wilson, Length-slope factors for the Revised Universal Soil Loss Equation: simplified method of estimation, Journal of Soil and Water Conservation. 47(1992) 423-428.

[29] W.E. Dietrich, C.I. Wilson, D.R. Montgomery, et al. Analysis of erosion thresholds, charmelnetworks, and landscape morphology using a digital terrain model, Journal of Geology. 101(1993) 259-278.

[30] F.X. Tian, Z.L. Wang, S.Q. Zheng, et al, Experiment modeling of soil erosion processes on Loess Roads based on simulated experiment. Bulletin of Soil and Water Conservation. 27(2007) 1-4. In Chinese.

[31] E.R. Burroughs, I.G. King, Reduction of soil erosion on forest roads, USDA Forest Service General Technical Report INT-264, Ogden, Utah, 1989. 